\title{
Diversity of endophytic fungi from the ornamental plant - Adenium obesum
}

\author{
Meenatchi $A^{1}$, Ramesh $V^{2}$, Bagyalakshmi ${ }^{1}$, Kuralarasi $\mathbf{R}^{1}$, Shanmugaiah $\mathrm{V}^{3}$, and \\ Rajendran $A^{1 \&^{*}}$
}

\author{
${ }^{1}$ Department of Botany, Virudhunagar Hindhu Nadar Senthikumara Nadar College, Virudhunagar- 626001 \\ ${ }^{2}$ Department of Botany, Vivekananda College, Tiruvedakam West, Madurai - 625234 \\ ${ }^{3}$ Department of Microbial Technology, School of Biological Sciences, Madurai Kamaraj University, Madurai - 625 \\ 021, Tamil Nadu, India1
}

Meenatchi A, Ramesh V, Bagyalakshmi, Kuralarasi R, Shanmugaiah V, Rajendran A 2016 Diversity of endophytic fungi from the ornamental plant- Adenium obesum. Studies in Fungi 1(1), 34-42, Doi 10.5943/sif/1/1/3

\begin{abstract}
Endophytic fungi live internally in apparently healthy and asymptomatic hosts. They are ubiquitous; no study has yet shown the existence of a plant species without endophytes. High species diversity is another characteristic of endophytic mycota. It is quite common for endophyte surveys to find assemblages consisting of more than 30species per host plant species.In the present study, 179 isolates were obtained from leaf, stem, and tissues of Adenium obesum collected from Virudhunagar, India. The endophytic fungi were identified based on the colony morphology and sporulating structures. Aspergillus sp. (28.5\%), Aspergilus breviceps (30\%), Colletotrichum gloeosporioides (23\%) and Scorpulariopsis brevicalis (17\%) were the most dominant species. The colonization frequency was higher in the winter season. Phyllosticta hymanaeae was isolated from leaf tissues during the summer and winter season. Aspergillus was the predominant genus isolated from all of leaf, stem and bark tissues of Adenium obesum.
\end{abstract}

Key words - Adenium obesum-colonization frequency - endophytes - seasonality

\section{Introduction}

Endophytes are microorganisms living in the internal tissues ofthe plants without causing any obvious symptoms (Suryanarayanan et al. 2010, Aly et al. 2011). Endophytic fungi have been reported from various plant species, which contribute to the diversity of microorganisms in natural environments (Nalini et al. 2014) and produce various bioactive compounds that play a major role in their inherent surroundings (Qadri et al. 2014, Tiwari et al. 2014). The term "Endophyte" was introduced by DeBary (1866) and was initially applied to any organism found within a plant that causes asymptomatic infections, entirely within plant tissues, without any symptoms of disease (Wilson 1995). By definition, an endophytic fungus lives in the mycelial form in association with living plants for at least for some time. Therefore, the minimal requirement before a fungus to be termed as an endophyte should be the demonstration of its hyphae in the living tissue (Kaul et al. 2012). During the past 30 years the terms endophyte and endophytic fungi have appeared frequently in the mycological literature to describe the internal mycota of living plants 
(Arivudainambi et al. 2011). Endophytic fungal isolates were found in the tissues of leaves, stem, bark and even in roots with mycorrhizae, symbionts and pathogens. The fungi associated with roots of higher plants are termed mycorrhizae (Campiet al.2015) and grow in symbiotic association with plants and both organisms benefit from this association (Rinaldiet al. 2008).

Most endophytes isolated to date have been ascomycetes and their asexual morphs, however Rungjindamai et al. (2008) showed that several endophytes may also basidiomycetes. Several studies provide evidence to support the hypothesis that saprobe host specificity in plants is dependent on internal endophytes, while others indicate that host components may regulate the endophytes (Paulus et al. 2006).There are numerous examples of endophytes that become pathogens (Brown et al. 1998). These pathogens sporulate when leaves senesce, or the plants are stressed or when the plants produce fruit that will eventually rot which is the ideal time to sporulate (Brown et al, 1998). Many recent studies have shown that endophytes produce an extraordinary array of functional metabolites (Schueffler \& Anke 2011, Tejesvi \& Pirttila 2011). Large numbers of metabolites are produced by so called "creative fungi" which include species of Acremonium, Aspergillus, Fusarium and Pencillium. Schulz et al. (2002) isolated around 6500 endophytic fungi and tested their biological potential. They analyzed 135 secondary metabolites and found that $51 \%$ of bioactive compounds (38\% for soil isolates) isolated from endophytic fungi were new natural compounds. Some endophytes may become slightly pathogenic to the plant under adverse conditions; other endophytes are able to suppress those latent pathogens (Mahesh et al. 2005)

Although the first discovery of endophytes already dates back to1904, this group ofmicroorganisms at first did not receive muchattention in the decades to follow (Freeman, 1904). This changed dramatically afterthe detection of paclitaxel in the endophytic fungus Taxomyces andreanae that was reported to be isolated from Taxus brevifolia, the latter being the original source of this important anti-cancer drug (Stierle et al. 1993, 1995). Medicinal plants are reported to harbour endophytes (Strobel 2002), which in turn provide protection to their host from infectiousagents and also provide adaptability to survive in adverse environmentalconditions. Endophytic fungi are known to have mutualistic relationsto their hosts, often protecting plants against herbivory, insect attack or tissue invading pathogens (Arivudainambi et al 2011). Ever since the discovery of the rich diversity of the endophytic fungi, their population dynamics, their role in improvingplant growth, plant health (Hallmann et al. 2007), their distribution in the plant, themetabolites they secrete and their potency to produce novelcompounds within the plants (Tan \& Zou 2001), have formed an important aspect of many research studies. There are approximately 300,000 plant species on earth and each individual plant is the host to one or more endophytes, and many of them maycolonize certain hosts (Strobel et al. 1993). The described populations of endophytic strains are few, which mean the opportunity to findnew strains and targeting natural products from endophytic microorganisms that colonize plants in different niches and ecosystemsis abundant.

Medicinal plants had been used to isolate and characterize directlythe bioactive metabolites. However, the discovery of fungal endophytes inside these plants with capacityto produce the same compounds shifted the focus of new drug sources from plants to fungi. Bioactive natural products from endophytic fungi, isolated from different plant species, are attracting considerableattention from natural product chemists and biologists alike, which is clearly depicted by the steady increase of publications devoted to this topic during the recent years. In the present study, the diversity and distribution of endophytic fungal species in Adenium obesum was explored.

\section{Materials \& Methods}

\section{Collection of samples}

Leaf, stem, and bark samples of Adenium obesum were collected during the winter (Dec to Feb) and summer (Apr to Jun) from in and around the Virudhunagar, Tamil Nadu, India. The samples were cut, labeled and placed separately in polythene bagsafter the removal of excess moisture. They were transferred to the laboratory and kept in a refrigerator at $4 . \mathrm{C}$. 


\section{Isolation of endophytes}

For the isolation of endophytic fungi, healthy leaves, stems and bark were washed in running tap water. Endophytic fungi were isolated according to the protocol of Devarajan et al. (2002) which was slightly modified following pilot studies. All the samples were washed twice in distilled water and then surface sterilized by immersion for $1 \mathrm{~min}$ in $70 \%(\mathrm{v} / \mathrm{v})$ ethanol, $4 \mathrm{~min}$ in sodium hypochlorite (3\% (v/v) available chlorine) and $30 \mathrm{~s}$ in $70 \%(\mathrm{v} / \mathrm{v})$ ethanol and further washed three times in sterilized distilled water for $1 \mathrm{~min}$ each time. After surface sterilization, the samples were aseptically cut into 5-7 $\mathrm{mm}$ pieces and transferred to Petri-plates containing potato dextrose agar (PDA) with $50 \mu \mathrm{g} / \mathrm{mL}$ of streptomycin to suppress bacterial growth. These Petri plates were incubated at $30^{\circ} \mathrm{C}$ with normal daily light and dark periods. The plates were examined daily for up to one month for the development of fungal colonies growing out from the leaf segments. The fungi growing out from the leaf tissue were subsequently transferred onto fresh PDA plates without antibiotics.

\section{Morphological characterization and identification}

The morphological characterization of the fungal isolates were observed and described based on the method of Photita et al. (2004). Further identification of fungal isolates was based on the standard taxonomic key included colony diameter, texture, colour, morphology of hyphae and conidia (Hyde et al. 2000).

\section{Maintenance of endophytes}

The endophytic fungal isolates were transferred separately to slants and accessioned accordingly depending upon the plant and plant parts from which they have been isolated. Finally the endophytic fungal isolates were maintained at $4^{\circ} \mathrm{C}$.

\section{Statistical Analysis:}

The percentage of Colonization frequency (\%), Periodicity of occurrence, Relative percentage occurrence (\%), Simpson and Shannon Diversity indices were calculated based on the standard methods.

\section{Colonization frequency $(\mathrm{CF} \%)$}

The colonization frequency ( $\mathrm{CF} \%$ ) of a single endophytic fungal species in the leaf segments were calculated by using the following formula (Suryanarayanan et al. 2003).

Number of segments colonized by fungi

$$
\mathrm{CF}(\%)=
$$

Total number of segments observed

\section{Relative percentage occurrence (RPO \%) of each group of fungi}

Relative percentage of occurrence (RPO\%) of different group of fungi viz., ascomycetes, coelomycetes, hypomycetes, xylariaceous and other fungi were calculated using the following formula (Lakshman et al. 2013).

$$
\text { RPO }(\%)=\frac{\text { Density of colonization of one fungal organism }}{\text { Total density of colonization of all fungal groups }} \times 100
$$

\section{Species diversity}

Shannon diversity index $\left(H^{\prime}\right)$, Shannon evenness index $\left(J^{\prime}\right)$ and Simpson diversity index (1/D) were used for theevaluation of fungal species richness (Brower 2004).

\section{Shannon-Wiener diversity}


Shannon-wiener diversity index was calculated using the following formula:

$\mathrm{sH}_{\mathrm{s}}=\Sigma(\mathrm{Pi})(\mathrm{In} \mathrm{Pi})$

$\mathrm{i}=1$

Where

$\mathbf{H}_{\mathbf{s}}=$ symbol for the diversity in a sample of $\mathbf{S}$ species or Kinds, $\mathbf{S}$-the number of species in the, sample Pi-relative abundance of $i^{\text {th }}$ species or kinds measures, $=n / N, \mathbf{N}$-total number of individuals of all kinds, $\mathbf{n}_{1}$-number of individuals of $i^{\text {th }}$ species, $\mathbf{1 n}-\log$ to base 2

\section{Simpson's Diversity}

$\mathrm{D}=1-\frac{\sum_{\mathrm{n}(\mathrm{n}-1)}}{\mathrm{N}(\mathrm{N}-1)}$

\section{Results}

A total of 179 isolates were obtained from two-hundred and ten segments of plant parts viz., leaf, stem, bark of $A$. obesum (Figs. $1 \& 2$ ). In the winter, 13 species belonging to 12 genera ( 6 hypomycetes and 6 coelomycetes) and two non sporulating sterile morphospecies were recovered from the leaves, stem, and bark tissues. In leaves, endophytic fungal colonization was dominated by Aspergillus sp. 2 (28.5\%), Colletotrichum gloeosporioides (22.9\%) and Scopulariopsis brevicalis (17.1\%), whereas Alternaria brassicola and Colletotrichum dematum showed low percentage of colonization. In stems, endophytic fungal colonization was dominated by Aspergillus brevipes (17.1\%), Aspergillussp.2 (20\%), whereas Colletotrichum dematum, Colletotrichum gloeosporioides and Sterile Form2 showed minimum percentage of colonization frequency. In bark Aspergillus brevipes (11.4\%) and Aspergillus sp.2 (14.3\%) showed maximum colonization frequency. In the summer, 12 species of fungi belonging to 12 genera (six hypomycetes and four coelomycetes) and a single non sporulating sterile morpho species were recovered from the leaves, stem, and bark tissues. In leaves, Aspergillus brevipes, Aspergillus sp.2 and Colletotrichum gloeosporioides showed maximum percentage of colonization frequency, while Alternaria brassicola and Phyllosticta hymanaeae showed minimum percentage of colonization. In stems, endophytic fungal colonization was dominated by Aspergillus brevipes, Nigrospora sphaerica and Colletotrichum gloeosporioides $(20 \%, 14.3 \%$ and $11.4 \%$ respectively).

Alternaria brassicola and sterile form 2 showed minimum percentage of colony frequency. In bark Aspergillus brevipes (17.1) showed maximum colonization frequency, whereas Nigrospora sphaerica, Colletotrichum gloeosporioides and Phyllosticta hymanaeae showed minimum colonization frequency (Table 1).

Number in parentheses designates the exact number of samplings in which the respective fungus was recorded.

Compared to summer (245), a great number of fungal isolates (274) were obtained from the leaves, stem and bark tissues of $A$. obesum in the winter season. A total of 14 species were isolated from the leaves of A. obesum from summer and winter season. Alternaria brassicola, Aspergillus brevipes, Aspergillus sp. 2, Colletotrichum dematium, C. falcatum, C. gloeosporioides, Curvularia lunata, Phyllosticta hymanaeae and Scopulariopsis brevicalis, were recorded as most common species in leaves and occurred in two samples. Chaetomium sp. 1 and Nigrospora sphaerica were recorded as occasional and occurred in only one sample. In stems, Alternaria brassicola, Aspergillus brevipes, Aspergillus sp. 2, Colletotrichum falcatum, C. gloeosporioides, Nigrospora sphaerica and Sterile Form 2 were recorded as most common and occurred in two samples. Chaetomium sp.1, Scopulariopsis brevicalis, Colletotrichum dematium and Phyllosticta hymanaeae were recorded as occasional and occurred in only one sample. In bark Aspergillus brevipes, Aspergillus sp.2, Nigrospora sphaerica, Colletotrichum falcatum and C. gloeosporioides were recorded as most common and occurred in two samples Chaetomium sp. 1, Alternaria brassicola, Curvularia lunata, Colletotrichum dematium, Phyllosticta hymanaeae, and Sterile Form 1 were recorded as occasional and occurred in only one sampling. Isolates of Chaetomium sp.1isolates 
were observed only in summer season. Phomasp.1 and sterile Form ${ }_{1}$ were isolated as endophyte only from during winter season (Table 2).

Table 1 Colonization frequency $(\mathrm{CF} \%)$ and relative percentage occurrence (RPO \%) of fungal endophytes isolated from the leaves, stem and bark of Adenium obesum

Endophytic fungi Winter Summer

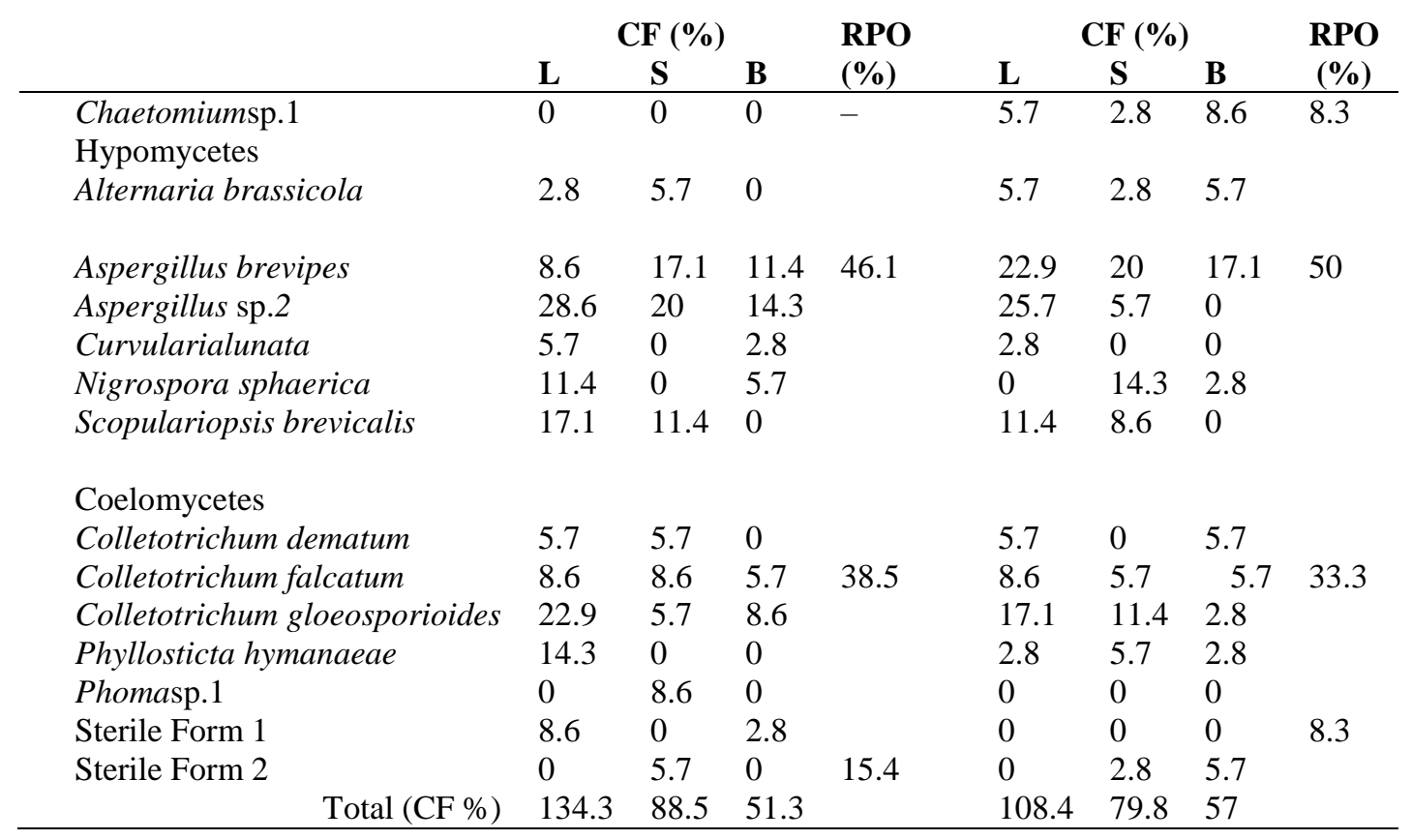

L -Leaves, S -Stemand B - Bark

Table 2 Periodicity of occurrence of endophytic fungi recorded from leaf, stem and bark of Adenium obesum during summer and winter

Leaf Stem $\quad$ Bark

Most Common: 51-100\%

Alternaria brassicola (2)

Aspergillu sbrevipes (2)

Aspergillus sp. 2 (2)

Curvularia lunata (2)

Scopulariopsis brevicalis (2)

Colletotrichum dematum (2)

Colletotrichum falcatum (2)

Colletotrichum gloeosporioides(2)

Phyllosticta hymanaeae (2)

Occasional 1-50\%

Chaetomium sp 1

Nigrospora sphaerica (1)
Most Common: 51-100\%

Alternariabrassicola (2)

Aspergillusbrevipes (2)

Aspergillus sp. 2 (2)

Nigrospora spherica (2)

Colletotrichum falcatum (2)

Colletotrichum gloeosporioides (2)

Sterile Form 2 (2)

Occasional 1-50\%

Chaetomium sp (1)

Scopulariopsis brevicalis (1)

Colletotrichum dematum (1)

Phyllosticta hymanaeae (1)
Most Common: 51-100\%

Aspergillus brevipes (2)

Aspergillus sp. 2 (2)

Nigrospora sphaerica (2)

Colletotrichumfalcatum (2)

Colletotrichum gloeosporioides (2)
Occasional 1-50\%

Chaetomium spp. (1)

Alternaria brassicola(1)

Curvularia lunata (1)

Colletotrichum dematum (1)

Phyllosticta hymanaeae (1)

Sterile Form 1 (1) 
The RPO (\%) of hyphomycetes, coelomycetes and sterile morphospecies were $46.1 \%$, $38.5 \%$, and $15.4 \%$ respectively in winter season. The RPO of Hhyphomycetes (50\%) was found to be maximum followed by coelomycetes (33.3\%) and ascomycetes (8.3) and sterile morphospecies $(3.3 \%)$ in summer season.

The Shannon and Simpson diversity indices of endophytic fungi of leaf stem and bark of Adenium obesum during winter season showed that the fungal diversity $(0.79 \& 0.89)$ in leaves has the high diversity indices. In summer season, the stem showed maximum diversity indices (0.89) and the leaves and bark showed minimum diversity indices (Table 3 ).

Table 3 Diversity indices of endophytic fungi associated with leaf, stem, and bark tissues of Adenium obesum.

\begin{tabular}{lcccccc}
\hline \multicolumn{1}{c}{ Diversity Indices } & \multicolumn{3}{c}{ Summer Season } & \multicolumn{3}{c}{ Winter season } \\
& L & S & B & L & S & B \\
\hline & & & & & & \\
Shannon diversity & 0.77 & 0.75 & 0.75 & 0.79 & 0.75 & 0.65 \\
Simpson Diversity & 0.87 & 0.89 & 0.88 & 0.89 & 0.89 & 0.86 \\
Invert Simpson Diversity & 7.69 & 9.09 & 8.3 & 9.09 & 9.09 & 7.14 \\
\hline
\end{tabular}

L-Leaf, S- Stem, B- Bark.

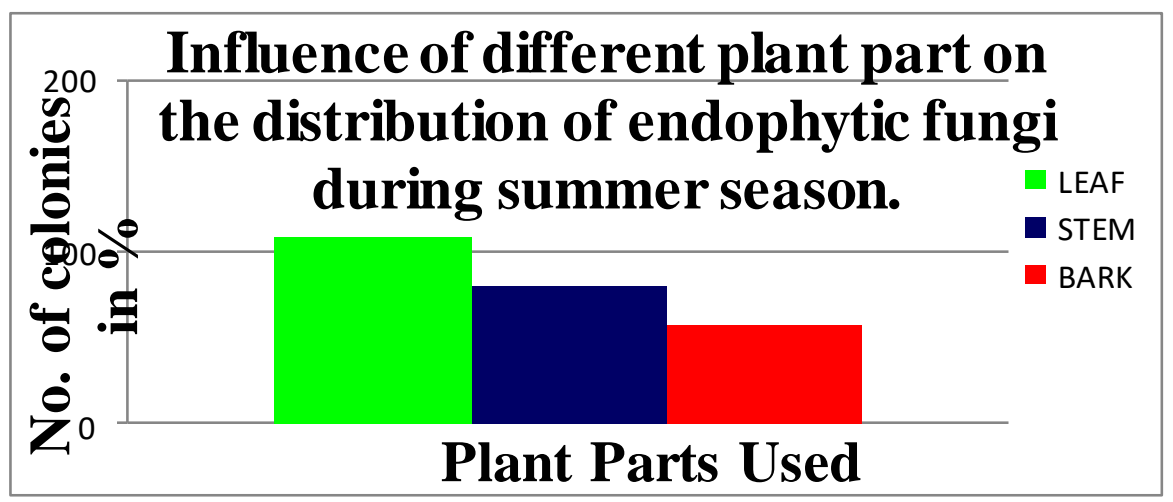

Fig. 1 - Distribution of endophytic fungi in A.obesum in summer season.

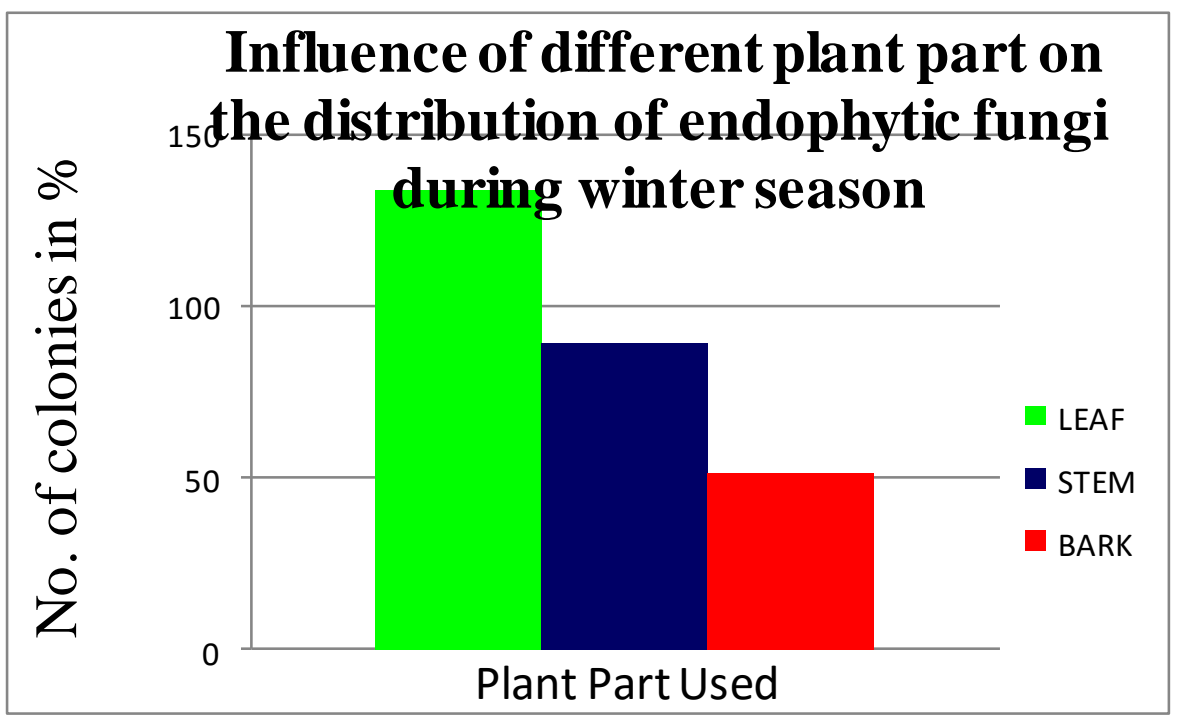

Fig. 2 - Distribution of endophytic fungi in A. obesum in winter season 


\section{Discussion}

As tropical and subtropical climates harbour most of the worlds plant diversity, so endophytic diversity in this climatic zone is also higher as almost all vascular plant species examined to date are found to possess endophytic bacteria and fungi (Firakovaet al. 2007). Plant colonization by endophytes may offer significant host benefits, improving ecological adaptability by enhancing tolerance to environmental stress (Khan et al. 2011, Stępniewska \& Kuźniar 2013).Moreover it was observed that the distribution of endophytic fungi varied in different plant parts. More number of fungal colonies were observed in leaf (134) than the stem (89) and bark (51) when compared with summer season. In summer season the endophytic fungal colonies was more in the leaf (108) than the stem (80) and bark (57) (Fig. 1\&2). So relatively, the colonization of endophytic fungi was highest in the leaf when compared to stem and bark. Leaves, petiole, stem and roots of a single plant often differ greatly in the dominant members of their endophytic communities (Chaverri et al.2010, Gazis et al. 2010), One of the possible reason for the differences in the colonization rates between plants is the structure and substrate which influence the colonization and distribution of endophytic fungi (Okane et al.1997). Similarly, Kumar \& Hyde (2004) also stated that the over all colonization rate in the leaves was found to be significantly higher than those in root, stem and petiole. Similarly, Roland et al. (2015) studied diversity of fungal endophytes Marchantia polymorpha populations from Baguio City, Philippines, Bijaya Kumar Nayak, (2015) isolated phylloplane and endophytic fungi from one ornamental plant, Mangifera indica, Martin \& Dombrowski (2015) isolated fungal Endophytes from grasses. Moreover, Thalavai pandian et al. (2011) isolated 270 fungal isolates were isolated from leaf, bark and stem tissues of gymnosperm plant. In contrast, Sunayana et al. (2014) reported higher number endophytic colonization were found in twig than the leaf segments.

Endophytic fungi of medicinally important host are the least investigated group of microorganisms which represent the untapped tool of bioactive and novel chemical compounds and could be exploited in agriculture, Pharmaceutical and neutraceutical industries in future. More discoveries of endophytes and their products from this field hold exciting promise, that is amply supported by the identification of wide variety of endophytic fungi. Hence, more studies on these groups of organisms are required to understand fungal biology, ecology and the mycologist will have the opportunity to gain more insight into the diversity of the fungal kingdom.

\section{Acknowledgments}

Authors thank the Managing Board of Virudhunagar Hindu Nadar's Senthikumara Nadar College, Virudhunagar-626 001, Tamil Nadu, India for providing research facilities.

\section{References}

Aly AH, Debbab A, Proksch P. 2011 - Fungal endophytes: unique plant inhabitants with great promises. Applied Microbiology and Biotechnology 90, 1829-1845.

Bijaya Kumar Nayak. 2015 - Isolation and identification of phylloplane and endophytic fungi from one ornamental plant, Mangifera indica. International Journal of TechnoChem Research 3, $188-192$.

Brower J, Zar J, Ende CV. 2004 - Field and laboratory methods for general ecology. Brown publishers.

Brown KB, Hyde KD, Guest DI. 1998 - Preliminary studies on endophytic fungal communities of Musa acuminate species complex in Hong Kong and Australia. Fungal Diversity1, 27-51.

Campi MG, Maubet YE, Britos L. 2015 - Mycorrhizal fungi associated with plantations of Pinus taeda L. from the National University of Asunción, Paraguay. Mycosphere 6, 486-492.

Chaverri P, Gazis R. 2010-Perisporiopsislateritia, a new species on decaying leaves of Hevea spp, From the Amazon basin in Peru. Mycotaxon 113, 163-169. 
De Bary A. 1866 - Morphologie und physiologie der plize, Flechten, and Myxomyceten (Hofmeister's Hand Book of Physiological Botany. Vol.2) Leipzig.

Devarajan PT, Suryanarayanan TS, Geetha V. 2002 - Endophytic fungi associated with the tropical seagrass Halophila ovalis (Hydrocharitaceae). Indian Journal of Marine Sciences 31, 73-74.

Firakova S, Sturdikova M, Muckova M. 2007 - Bioactive secondary metabolites produced by microorganisms associated with plants. Biologia 62, 251-257.

Fisher PJ, Sutton, BC, Petrini LE, Petrini O. 1994 - Fungal endophytes from Opuntia stricta: a first report. Nova Hedwigia 59, 195-200.

Freeman EM. 1904 - The seed fungus of Lolium temulentum L.Phil. Transitions in Royal Societiy of London Biology 196, 1-27.

Gazis R, Chaverri P. 2010 - Diversity of fungal endophytes in leaves and stem of wild rubber trees (Hevea brasiliensis) IN Peru Fungal Ecology 3, 320.

Hallmann J, Berg G, Schulz. 2007 - Isolation procedures for endophytic microorganism Springer Brelin Heidelberg, New York.

Hyde KD, Taylor JE, Fröhlich J. 2000 - Genera of Ascomycetes from Palm. Fungal Diversity Press, Hong Kong.

Hyde KD. 2004 - Biodiversity and tissue recurrence of endophytic fungi in Tripterygium wilfordii. Fungal Diversity 17, 69-90.

Kaul S, Gupta S, Ahmed M, Dhar MK. 2012 - Endophytic fungi from medicinal plants: a treasure hunt for bioactive metabolites. Phytochemistry Review 11, 487-505.

Khan AL, Hamayun M, Ahmad N, Waqas M, et al. 2011 - Exophiala sp LHL08 reprograms Cucumis sativus to higher growth under abiotic stresses. Physiol. Plant 143: 329-343.

Lakshman HC, Urandawad JM. 2013 - Diversity of the endophytic fungi isolated from Spilanthes acmella - promising medicinal plant. International Journal of Pharmaceutical BioSciences 4, $1259-1266$.

Mahesh B, Tejesvi MV, Nalini MS, Rakish HS, Kini KR, Subbiah V Shetty HS. 2005 Endophytes mycoflora of inner bark of Azadirachta indica. Current Science 88, 218-219.

Martin RC, Dombrowski JE. 2015 - Isolation and Identification of Fungal Endophytes from Grasses along the Oregon Coast. American Journal of Plant Sciences 6, 3216-3230.

Hipo RM, Tamang SMA, Gargabite BF, Broñola Hipol RLC. 2015 - Diversity of fungal endophytes isolated from Marchantia polymorpha populations from Baguio City, Philippines. Bulletin of Environment, Pharmacology and Life Sciences 4, 87-91.

Nalini MS, Sunayana N, Prakash HS. 2014 - Endophytic fungal diversity in medicinal plants of Western Ghats, India. International Journal of Biodiversity (doi.org/10.1155/2014/494213).

Okane I, Nagagiri A. 1997 - Preliminary study of endophytic fungi in ever green plants from Ishigaki and Iriomote islands. Osaka Research Communications 18, 45-51.

Paulus B, Kanowski J, Gadek P, Hyde KD. 2006 - Diversity and distribution of saprobic microfungi in leaf litter of an Australian tropical rain forest. Mycological Research 110, 1441-1454.

Petrini O, Fisher PJ, Petrini LE. 1992 - Fungal endophytes of bracken (Pteridium aquilinum) with some reflections on their use in biological control. Sydowia 44, 282-293.

Photita W, Lumyong S, Lumyong P, Mckenzie EHC, Hyde KD. 2004 - Are some endophytes of Musa acuminate latent pathogens? Fungal Diversity 16, 131-140.

Qadri M, Rajput R, Abdin MZ, Vishwakarma RA, Riyaz-Ul-Hassan S. 2014 - Diversity, molecular phylogeny, and bioactive potential of fungal endophytes associated with the Himalayan blue pine (Pinus wallichiana). Microbial Ecology 67, 877-887.

Rinaldi AC, Comandini O, Kuyper TW. 2008 - Ectomycorrhizal fungal diversity: separating the wheat from the chaff.FungalDiversity33, 1-45.

Rungjindamai N, Pinruan U, Choeyklin R, Hattori T, Jones EBG. 2008 - Molecular characterization of basideomycetous endophytes isolated from leaves, rachis petioles of the oil palm. Elaeis guineensis in Thailand. Fungal Diversity 33, 139-161. 
Schueffler A, Anke T. 2011 - Antimicrobial compounds from tree endophytes. In: (Eds. A.M. Pirttilä and A.C. Frank) Endophytes of Forest Trees: Biology and Applications. New York, Springer. 265-294.

Schulz B, Boyle C, Draeger S, Rommert AK. 2002 - Endophytic fungi: a source of novel biologically active secondary metabolites. Mycological Research 106, 996-1004.

Shankar Naik B, Shashikala J, Krishnamurthy YL. 2008 - Diversity of endophytic fungal communities in shrubby medicinal plants of Western Ghats region, Southern India. Fungal Ecology 1, 89-93.

Stępniewska Z and Kuźniar A. 2013 - Endophytic microorganisms promising applications in bioremediation of greenhouse gases. Applied Microbiology and Biotechnology 97, 95899596.

Stierle A, Strobel GA, Sterile D, Grothaus P, Bignami G. 1995 - The search for a taxol producing microorganism among the endophytic fungi of the Pacific yew, Taxus brevifolia. Journal of Natural Product 58, 1315-1324.

Strobel GA, Stierle A, Stierle D, Hess WM. 1993 - Taxomyces andreanae a proposed new taxon for a bulbilliferous hyphomycete assiciated with Pacific yew. Mycotaxon 47, 71-78.

Stierle A, Strobel GA, Stierle D. 1993 - Taxol and taxane production by Taxomyces andreanae, an endophytic fungus of Pacific Yew. Science 9, 214-216.

Strobel GA. 2002 - Rainforest endophytes and bioactive products. Critical Review in Biotechnology 22, 315-333.

Sunayana N, Nalini MS, Sampath Kumara KK Prakash HS. 2014 - Diversity studies on the endophytic fungi of Vitex negundo L. Mycosphere 5, 578-590

Suryanarayanan TS, Venkatachalam A, Thirunavukkarasu N, Ravishankar JP, Doble M, Geetha V. 2010 - Internal mycobiota of marine macroalgae from the Tamil Nadu coast: distribution, diversity and biotechnological potential. Botanica Marina 53, 457-468.

Suryanarayanan TS, Venkatesan G Murali TS. 2003 - Endophytic fungal communities in leaves of tropical forest trees: Diversity and distribution patterns. Current Science 85, 489-492.

Tan RX, Zou WX. 2001- Endophytes: a rich source of functional metabolites. Natural Products Report 18, 448-459.

Tejesvi MV, Pirttilä AM. 2011 - Potential of tree endophytes as sources for new drug compounds. In: (Eds. A.M. Pirttilä and A.C. Frank) Endophytes of Forest Trees: Biology and Applications. New York, Springer. 295-311.

Thalavaipandian A, Ramesh V, Bagyalakshmi T, Muthuramkumar S, Rajendran. 2011 - Diversity of fungal endophytes in medicinal plants of Courtallam hills, WesternGhats, India. Mycosphere 2, 575-582.

Tiwari S, Singh S, Pandey P, Saikia SK, Negi AS, Gupta SK, Pandey R, Banerjee S. 2014 Isolation, structure determination, and anti-aging effects of 2,3-pentanediol from endophytic fungus of Curcuma amada and docking studies. Protoplasma DOI 10.1007/s00709-014-0617-0.

Wilson 1995 - Endophytes: the evolution of a term and clarification of its use and definition. Oikos 73, 274-276.

Yang X, Strobel G, Clardy J. 1993- A fungal endophyte- tree relationship: Phoma sp. In Taxus Wallachiana. Plant Science 102, 1-9. 